\title{
Novel metabolic features in Acinetobacter baylyi ADP1 revealed by a multiomics approach
}

\author{
Lucille Stuani · Christophe Lechaplais • Aaro V. Salminen • Béatrice Ségurens • \\ Maxime Durot • Vanina Castelli $\cdot$ Agnès Pinet $\cdot$ Karine Labadie • \\ Stéphane Cruveiller · Jean Weissenbach · Véronique de Berardinis • \\ Marcel Salanoubat • Alain Perret
}

Received: 20 November 2013/Accepted: 7 April 2014/Published online: 29 April 2014

(C) The Author(s) 2014. This article is published with open access at Springerlink.com

\begin{abstract}
Expansive knowledge of bacterial metabolism has been gained from genome sequencing output, but the high proportion of genes lacking a proper functional annotation in a given genome still impedes the accurate prediction of the metabolism of a cell. To access to a more global view of the functioning of the soil bacterium Acinetobacter baylyi ADP1, we adopted a multi 'omics' approach. Application of RNA-seq transcriptomics and LC/MS-based metabolomics, along with the systematic phenotyping of the complete collection of single-gene deletion mutants of $A$. baylyi ADP1 made possible to interrogate on the metabolic perturbations encountered by
\end{abstract}

Electronic supplementary material The online version of this article (doi:10.1007/s11306-014-0662-x) contains supplementary material, which is available to authorized users.

L. Stuani - C. Lechaplais - A. V. Salminen - B. Ségurens .

M. Durot · V. Castelli · A. Pinet - K. Labadie - S. Cruveiller ·

J. Weissenbach · V. de Berardinis · M. Salanoubat · A. Perret $(\square)$

Direction des Sciences du Vivant, Commissariat à l'Energie

Atomique et aux Energies Alternatives (CEA), Institut de

Génomique, Evry, France

e-mail: aperret@genoscope.cns.fr

L. Stuani - C. Lechaplais - A. V. Salminen - B. Ségurens .

M. Durot - V. Castelli - A. Pinet - K. Labadie - S. Cruveiller

J. Weissenbach · V. de Berardinis - M. Salanoubat - A. Perret

CNRS-UMR8030, Evry, France

L. Stuani - C. Lechaplais - A. V. Salminen - B. Ségurens · M. Durot · V. Castelli · A. Pinet · K. Labadie - S. Cruveiller . J. Weissenbach · V. de Berardinis · M. Salanoubat - A. Perret Université d'Evry Val d'Essonne, Evry, France

A. V. Salminen

Department of Chemistry and Bioengineering, Tampere

University of Technology, Korkeakoulunkatu 10,

33720 Tampere, Finland the bacterium upon a biotic change. Shifting the sole carbon source from succinate to quinate elicited in the cell not only a specific transcriptional response, necessary to catabolize the new carbon source, but also a major reorganization of the transcription pattern. Here, the expression of more than $12 \%$ of the total number of genes was affected, most of them being of unknown function. These perturbations were ultimately reflected in the metabolome, in which the concentration of about $50 \%$ of the LC/MSdetected metabolites was impacted. And the differential regulation of many genes of unknown function is probably related to the synthesis of the numerous unidentified compounds that were present exclusively in quinate-grown cells. Together, these data suggest that A. baylyi ADP1 metabolism involves unsuspected enzymatic reactions that await discovery.

Keywords LC/MS-LTQ-Orbitrap · Metabolomics . Transcriptomics $\cdot$ Functional genomics $\cdot$ Bacterial metabolism

\section{Introduction}

Extensive insights into the metabolism of microbial organisms have been gained from whole genome sequencing and annotation projects. Nevertheless, with approximately $30 \%$ of genes of a typical genome with no assigned function, the genome mining alone cannot report for the vast diversity in the lifestyle and metabolic functions observed in the bacterial world. To this end, functional genomics, which aims at the elucidation of the molecular basis of biological functions, requires analyses that go far beyond the primary analysis of the genome sequence. Technologies such as phenomics, transcriptomics, and metabolomics are complementary tools 
for exploring the metabolic state of microorganisms, allowing a more global view of the functioning of a cell. Acinetobacter spp. are gram-negative bacteria that are ubiquitously distributed in nature. Unique among this highly heterogeneous bacterial genus (Ibrahim et al. 1997) is strain ADP1, a soil bacterium characterized by a small genome $(3.6 \mathrm{Mb})$ in which genes encoding most catabolic functions are clustered in several genetic islands (Barbe et al. 2004; Young et al. 2005). Its extraordinary competence for natural transformation and the ease with which it can be genetically engineered (de Berardinis et al. 2009; Metzgar et al. 2004) make ADP1 a key organism for the study of metabolism.

ADP1 is a nutritionally versatile bacterium capable of metabolizing a wide range of aromatic compounds as the sole source of carbon and energy (Barbe et al. 2004). The main route for the degradation of aromatic molecules to the point where they can enter central metabolism is the $\beta$-ketoadipate pathway through catechol and protocatechuate (Young et al. 2005). The main features of the $\beta$-ketoadipate pathway have been described in detail (Harwood and Parales 1996). From catechol and protocatechuate, a parallel but separate branch converts them into succinyl-CoA and acetyl-CoA which can enter central metabolism through the TCA cycle (Fig. 1). Most of the genes involved in the degradation of aromatic compounds that feed into the catechol branch are colocalized with those for catechol degradation, forming one island of catabolic genes. This cluster contains the sal-are-ben-cat genes (ACIAD1424 to ACIAD1451). On the other hand, most of the genes that metabolize aromatic substrates feeding into the protocatechuate branch are colocalized with those for protocatechuate degradation and form another island of catabolic genes, which contains the pca-qui-pob-hca genes (ACIAD1702 to ACIAD1728).

Quinate is an alicyclic compound that feeds into the protocatechuate branch. Its conversion to protocatechuate takes place in the periplasm, where quinate dehydrogenase (QuiA) oxydates quinate to dehydroquinate, which is then dehydrated by dehydroquinate dehydratase (QuiB) to produce dehydroshikimate. This latter is further dehydrated by dehydroshikimate dehydratase (QuiC) to produce protocatechuate which is then translocated in the cytoplasm for further degradation (Young et al. 2005). Quinate dissimilation is performed by 14 genes, 3 code for 2 transporters and 1 regulator, the remaining being involved in enzymatic activities. In sum, the biochemical and genetic features of quinate degradation in ADP1 have been thoroughly investigated for many years (for review, see Young et al. 2005). In contrast, the question on the genes and enzymes activated by quinate and how they are differentially regulated, at the genome scale, remains largely unanswered.

In this work, we have adopted a multi 'omics' approach for interrogating on the metabolic perturbations encountered
Fig. 1 The complete pathway for aromatic catabolism in A. baylyi ADP1. Enzymes are labeled within boxes by their genetic notation. Unnamed metabolites are labeled with circled numbers: 1 benzoate, 2 1,2-dihydro-1,2-dihydroxybenzoate (benzoate cis-glycol), 3 anthranilate, 4 salicylate, 5 alkyl salicylates, 6 benzylalkanoates, 7 benzyl alcohol, 8 benzaldehyde, 9 2-hydroxybenzylalkanoates (salicylalkanoates), 10 2-hydroxybenzyl alcohol, 11 2-hydroxybenzaldehyde, 12 4-hydroxybenzylalkanoates, 13 4-hydroxybenzyl alcohol, 14 4-hydroxybenzaldehyde, 15 4-hydroxybenzoate ( $p$-hydroxybenzoate), 16 vanillate, 17 chlorogenate, 18 ferulate, 19 ferulyl-CoA, 20 vanillaldehyde, 21 -coumarate, 22 -coumaryl-CoA, 23 4-hydroxybenzaldehyde, 24 caffeate, 25 caffeyl-CoA, 26 protocatechualdehyde, 27 4-hydroxyphenylpropionate, 28 3,4-dehydroxyphenylpropionylCoA. Adapted from (Williams and Kay 2008)

by ADP1 when the sole source of carbon and energy shifted from succinate to quinate. To this end, we reexamined the systematic phenotyping of our collection of approximately 2,400 deletion mutants (de Berardinis et al. 2008) on liquid medium containing quinate as the sole carbon source, for detecting the genes involved in its catabolism. And for the first time, we report the use of RNA-seq transcriptomics and LC/MS-based metabolomics for exploring the metabolic response of ADP1 to face this environmental change. The comparison of expression profiles in quinate versus those in succinate confirmed the participation of the genes known to dissimilate quinate, but especially revealed a major reorganization of the transcription pattern of ADP1. This led in turn in a dramatic change in the metabolome, in which about $50 \%$ of intracellular LC/MS-detected metabolites had their concentration changed. Together, these results indicated that the carbon source shift did not only induce the specific transcriptional response necessary to face the environmental change (i.e. the catabolism of the new carbon source) but also suggested a more global metabolic reprogramming. Finally, the differential regulation of many genes of unknown function along with the accumulation of metabolites of unknown identity suggest that unsuspected metabolic pathways take place during growth on quinate.

\section{Materials and methods}

\subsection{Chemicals and reagents}

Agarose $\left(\right.$ Seakem ${ }^{\circledR}$ GTG $\left.^{\mathrm{TM}}\right)$ was purchased from Lonza. PTFE membrane filters (JH Omnipore $0.45 \mu \mathrm{m}$ ) were from Millipore. Cryogenic vials (T3082A) were from Simport. HPLC-grade solvents, ammonium acetate, ammonium carbonate, ammonium hydroxide, formic acid, and metabolite standards were from Sigma-Aldrich. 3-dehydroquinate was prepared from quinate and cell crude lysate containing quinate dehydrogenase (see Online Resource 1, Protocol S-1). 


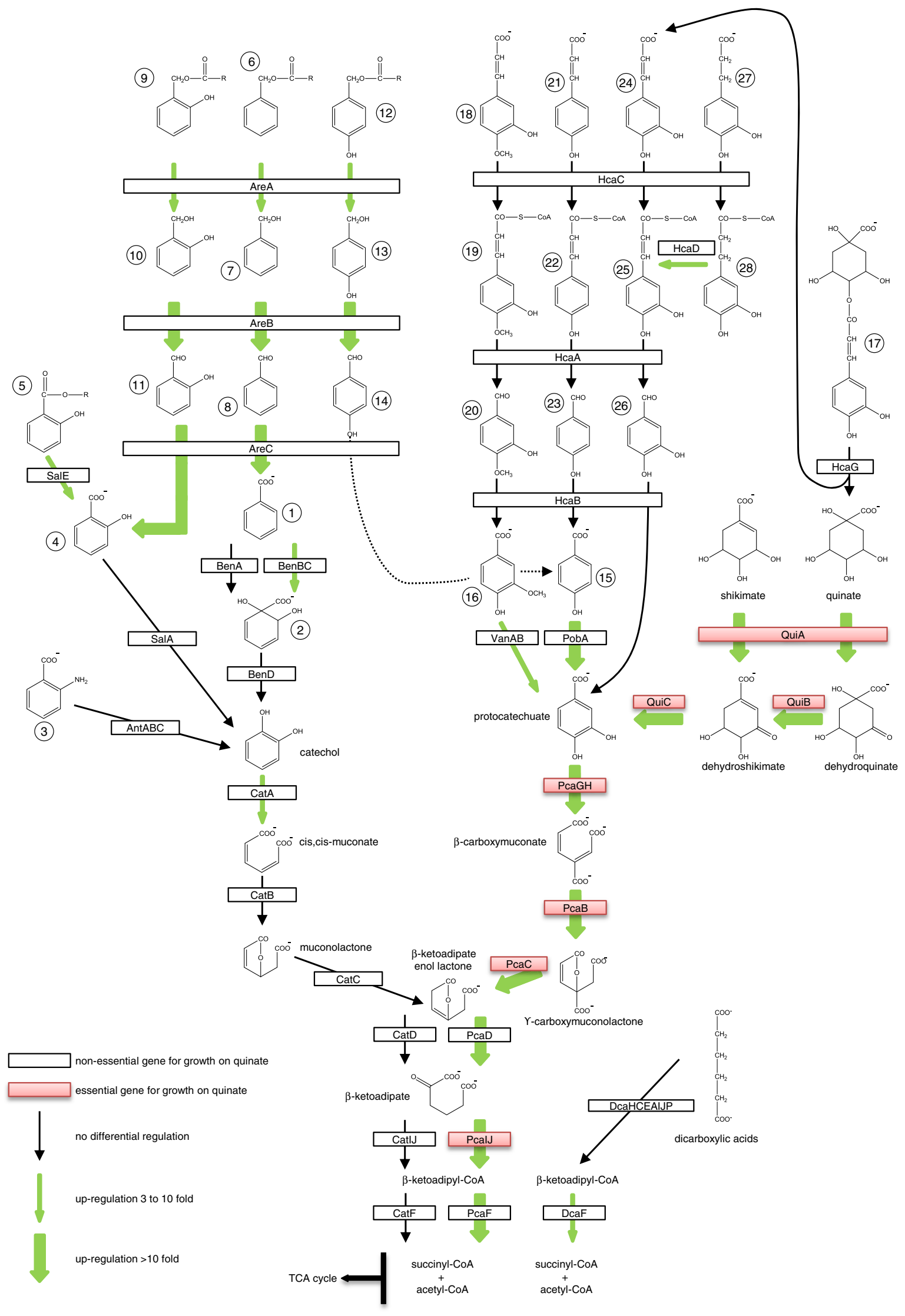




\subsection{Strain and media}

The A. baylyi ADP1 strain (DSM 24193) was provided by Dr. Nicholas Ornston (Yale University). Cells were routinely grown on MA (Medium for Acinetobacter) minimal medium [31 mM Na ${ }_{2} \mathrm{HPO}_{4}, 25 \mathrm{mM} \quad \mathrm{KH}_{2} \mathrm{PO}_{4}, 18 \mathrm{mM}$ $\mathrm{NH}_{4} \mathrm{Cl}, 41 \mathrm{mM}$ nitrilotriacetic acid, $2 \mathrm{mM} \mathrm{MgSO}_{4}$, $0.45 \mathrm{mM} \mathrm{CaCl}_{2}, 3 \mathrm{mM} \mathrm{FeCl}_{3}, 1 \mathrm{mM} \mathrm{MnCl}$, $1 \mathrm{mM} \mathrm{ZnCl}$, $0.3 \mathrm{mM}\left(\mathrm{CrCl}_{3}, \mathrm{H}_{3} \mathrm{BO}_{3}, \mathrm{CoCl}_{2}, \mathrm{CuCl}_{2}, \mathrm{NiCl}_{2}, \mathrm{Na}_{2} \mathrm{MoO}_{2}\right.$, $\mathrm{Na}_{2} \mathrm{SeO}_{3}$ )] supplemented with $25 \mathrm{mM}$ of the desired carbon source.

\subsection{Construction of the deletion mutants}

PCR primers are listed in Online Resource 1, Table S-1. Generation of the integration cassette, transformation and mutant selection were conducted as previously reported (de Berardinis et al. 2008). $\triangle$ ACIAD3353 and $\triangle$ ACIAD1738 were first selected on MA supplemented with $25 \mathrm{mM}$ succinate and $30 \mu \mathrm{g} / \mathrm{ml}$ kanamycine, and containing $25 \mathrm{mM}$ shikimate to allow aromatic amino acid biosynthesis. The clones were then replicated on MA supplemented with succinate and on MA supplemented with quinate.

\subsection{RNA-seq transcriptomics}

\subsubsection{Culture conditions for RNA preparation}

Duplicate liquid cultures of ADP1 were grown at $30^{\circ} \mathrm{C}$ in MA minimal medium supplemented with $25 \mathrm{mM}$ of each of the desired carbon source and shaken at $150 \mathrm{rpm}$. Overnight cultures were used to inoculate (1:100 dilution) $100 \mathrm{ml}$ of fresh medium. Cultures were grown at $30{ }^{\circ} \mathrm{C}$ and $150 \mathrm{rpm}$ to a final OD of $0.6-0.7$ at $600 \mathrm{~nm}$ (mid-log phase), and stopped by adding $12.5 \mathrm{ml}$ of RNA stabilization buffer $(2.5 \%$ phenol-acetate $25 \mathrm{mM} \mathrm{pH}$ $5.5+95 \%$ ethanol). Bacteria were collected by centrifugation $\left(4{ }^{\circ} \mathrm{C}\right.$ for $3 \mathrm{~min}$ at $6,000 \mathrm{~g}$ ) and suspended in $20 \mathrm{ml}$ of Tri Reagent ${ }^{\circledR}$ (Sigma-Aldrich) for RNA extraction and stored at $-20{ }^{\circ} \mathrm{C}$. Total RNA was isolated according to the Tri Reagent ${ }^{\circledR}$ supplier protocol. Residual genomic DNA was removed using Ambion DNase Turbo $^{\circledR}$ (Life Technologies) and DNA degradation was checked by PCR with primers designed for selected ORFs to measure the contamination of residual genomic DNA. RNA integrity was analyzed using an Agilent 2100 bioanalyzer (Agilent technologies, Santa Clara, CA, USA). Ribosomal RNA was removed by Ambion MICROBExpress ${ }^{\circledR}$ and MEGAclear ${ }^{\circledR}$ treatments. To evaluate the degree of rRNA depletion, samples were analyzed on an Agilent 2100 bioanalyzer. The RNA Integrity Number (RIN) of total RNA was $>7$.

\subsubsection{Fragmentation of RNA}

0.5-1 $\mu$ g RNA was fragmented to size between 100 and $200 \mathrm{nt}$ using RNA Fragmentation Buffer (5×: $200 \mathrm{mM}$ Tris/acetate, $\mathrm{pH} 8.1,500 \mathrm{mM}$ KOAc, $150 \mathrm{mM} \mathrm{MgOAc}$ ), based on metal-catalyzed heat fragmentation. $4 \mu \mathrm{l}$ of $5 \times$ RNA Fragmentation Buffer were added to $16 \mu$ l of RNA and incubated for $3 \mathrm{~min}$ at $94{ }^{\circ} \mathrm{C}$. The reaction was terminated by adding $2 \mu \mathrm{l}$ of Stop Solution (containing a metal chelating agent) and chilled on ice. RNA was then purified on a RiboMinus ${ }^{\mathrm{TM}}$ Concentration Module (Life Technologies). The fragmented RNA was dephosphorylated using $2 \mathrm{U}$ Antarctic phosphatase (New England Biolabs) at $37{ }^{\circ} \mathrm{C}$ for $30 \mathrm{~min}$, and $5^{\prime}$ phosphorylated using $20 \mathrm{U}$ T4 polynucleotide Kinase (New England Biolabs) at $37{ }^{\circ} \mathrm{C}$ for $60 \mathrm{~min}$. The reaction product was purified with the RiboMinus $^{\mathrm{TM}}$ Concentration Module.

\subsubsection{3' adapter ligation}

The $3^{\prime}$ adapter was ligated to the RNA fragments as follows: $5 \mu \mathrm{lmRNA}(0.5-1 \mu \mathrm{g})$ and $1 \mu \mathrm{l} 3^{\prime}$ adapter $(100 \mu \mathrm{M})$ were pre-heated at $70{ }^{\circ} \mathrm{C}$ for $2 \mathrm{~min}$ and immediately placed on ice, to minimize secondary structure formation. $2 \mu \mathrm{l} 5 \times$ HM Ligation Buffer (supplied with Illumina TruSeq Small RNA Sample Prep Kit) were added with $1 \mu$ l RNasin ${ }^{\circledR}$ RNase inhibitor (Promega) and 200 U T4 RNA Ligase 2, truncated (New England Biolabs). The reaction was performed for $1 \mathrm{~h}$ at $28{ }^{\circ} \mathrm{C}$ followed by $15 \mathrm{~min}$ at $28{ }^{\circ} \mathrm{C}$ in the presence of $1 \mu \mathrm{l}$ of stop solution (STP) and placed on ice to inactivate the enzyme.

\subsection{4 $5^{\prime}$ adapter ligation}

The $5^{\prime}$ adapter was ligated as follows: $1 \mu \mathrm{l}$ of $5^{\prime}$ adapter $(100 \mu \mathrm{M})$ was pre-heated at $70{ }^{\circ} \mathrm{C}$ for $2 \mathrm{~min}$ and chilled on ice. The pre-heated $5^{\prime}$ adapter was then added to the $3^{\prime}$ adapter ligation reaction product in the presence of $1 \mu \mathrm{l}$ ATP (10 mM) and $20 \mathrm{U}$ of T4 RNA Ligase 1 (New England Biolabs). The ligation reaction was performed for $1 \mathrm{~h}$ at $28{ }^{\circ} \mathrm{C}$ and chilled on ice.

\subsubsection{First strand reverse transcription and PCR amplification}

Six microlitre of the $5^{\prime}$ and $3^{\prime}$ adapter-ligated RNA and $1 \mu \mathrm{l}$ of the Illumina RT primer $(100 \mu \mathrm{M})$ were pre-heated at $70{ }^{\circ} \mathrm{C}$ for $2 \mathrm{~min}$ and placed on ice. Next, $2 \mu \mathrm{l} 5 \times$ FirstStrand Buffer (250 mM Tris/HCl pH 8.3, $375 \mathrm{mM} \mathrm{KCl,}$ $15 \mathrm{mM} \mathrm{MgCl}{ }_{2}$; Invitrogen), $0.5 \mu \mathrm{l} 12.5 \mathrm{mM}$ dNTP, $1 \mu \mathrm{l}$ $100 \mathrm{mM}$ DTT, $1 \mu \mathrm{l} \mathrm{RNasin}{ }^{\circledR}$ RNase inhibitor, and $200 \mathrm{U}$ of SuperScript ${ }^{\mathrm{TM}}$ II reverse transcriptase (Invitrogen) were added and allowed the first strand synthesis to proceed for 
$1 \mathrm{~h}$ at $50{ }^{\circ} \mathrm{C}$ and was then chilled on ice. The first strand was amplified in a PCR reaction containing $12.5 \mu \mathrm{l}$ of ssDNA, $10 \mu \mathrm{l} 5 \times$ Phusion ${ }^{\circledR}$ HF Buffer (New England Biolabs), $2 \mu$ RNA PCR Primer (RP1 supplied with Illumina TruSeq Small RNA Sample Prep Kit), $2 \mu$ l RNA PCR Primer Index (RPIX containing a unique 6-bases index sequence), $0.5 \mu 125 \mathrm{mM}$ dNTP and $0.5 \mu \mathrm{l}$ of Phusion ${ }^{\circledR}$ High-Fidelity DNA polymerase. The PCR protocol used for the libraries was as follows: $30 \mathrm{~s}, 98^{\circ} \mathrm{C} / 12 \times$ $\left(10 \mathrm{~s}, 98{ }^{\circ} \mathrm{C} / 30 \mathrm{~s}, 60{ }^{\circ} \mathrm{C} / 15 \mathrm{~s}, 72{ }^{\circ} \mathrm{C}\right) / 10 \mathrm{~min}, 72{ }^{\circ} \mathrm{C} /$ hold at $4{ }^{\circ} \mathrm{C}$. Libraries were purified using AMPure beads (Agencourt Bioscience) according to the Directional mRNA-seq library preparation v1.0.

\subsubsection{DNA sequencing}

Libraries were purified and then quantified using a Qubit Fluorometer (Life technologies) and libraries profiles were evaluated using an Agilent 2100 bioanalyzer (Agilent Technologies, USA). Libraries were loaded at a concentration of $12 \mathrm{pM}$ per flow cell lane and sequenced on the Illumina GAIIx instrument using 76 base-length read chemistry in a single flow cell, following manufacturer instructions. Image analysis and base calling were performed using Illumina pipeline v 1.6.

\subsubsection{RNA-Seq analysis}

Transcriptomic high throughput sequencing data were analyzed using a bioinformatic pipeline implemented in the Microscope platform (Vallenet et al. 2013). The current pipeline was a "Master" shell script that launches the various parts of the analysis (i.e. a collection of Shell/Perl/ $\mathrm{R}$ scripts) and controls for all tasks having been completed without errors. In a first step, the RNA-seq data quality was assessed by including option like reads trimming or merging/split paired-end reads. In a second step, reads were mapped onto ADP1 genome sequence (GenBank accession no CR543861) using the SSAHA2 package (Ning et al. 2001) that combined the SSAHA searching algorithm (sequence information is encoded in a perfect hash function) aiming at identifying regions of high similarity, and the cross-match sequence alignment program (Ewing et al. 1998), which aligned these regions using a banded Smith-Waterman-Gotoh algorithm (Smith and Waterman 1981). An alignment score equal to at least half of the read was required for a hit to be retained. To lower false positives discovery rate, the SAMtools (v.0.1.8) (Li et al. 2009) were then used to extract reliable alignments from SAM formatted files. The number of reads matching each genomic object harbored by the reference genome was subsequently computed with the Bioconductor-GenomicFeatures package (Carlson 2011). If reads matching several genomic objects, the count number was weighted in order to keep the same total number of reads. Finally, the Bioconductor-DESeq package (Anders and Huber 2010) with default parameters was used to analyze raw counts data and test for differential expression between conditions.

Genes were considered up-regulated relative to succinate if the number of corresponding reads increased at least threefold (padj $<0.05$ ). Conversely, genes were considered down-regulated if the number of reads decreased at least threefold (padj < 0.05).

\subsection{Metabolomics}

\subsubsection{Metabolome preparation}

Six independent cultures were grown on each carbon source (the experimental design is described in Online Resource 1, Figure S-1). Metabolite extraction was adapted from (Brauer et al. 2006). A saturated overnight minimal media liquid culture was diluted in a fresh liquid media at an $\mathrm{OD}_{600}=0.05$, and further grown to an $\mathrm{OD}_{600}=0.2$. $5 \mathrm{ml}$ of this culture were filtered onto a $47 \mathrm{~mm}$ PTFE filter $(0.45 \mu \mathrm{m})$. The filter was then positioned with cells on top on an agarose plate containing the same minimal media. Cells were grown to log phase $\left(\mathrm{OD}_{600} \sim 0.8\right)$. Metabolism was quenched by placing the filter containing the cells face-down in a glass dish containing $5 \mathrm{ml}$ of a cold $\left(-30{ }^{\circ} \mathrm{C}\right)$ mixture of $80 \%$ acetonitrile and $20 \%$ methanol. After $15 \mathrm{~min}$ at $-30^{\circ} \mathrm{C}$, the filter coated with cells was submitted to a mild sonication in an ultrasonic bath (Bronson 2510 Ultrasonic Cleaner) for $5 \mathrm{~min}$ at $4{ }^{\circ} \mathrm{C}$ to remove the cells from the filter. The quenching liquid containing the cells was transferred into a cryogenic vial and underwent 6 freeze/thaw cycles in liquid nitrogen/ $65{ }^{\circ} \mathrm{C}$ water to fully break the cells and extract the metabolites. The samples were lyophilized and first dissolved in $300 \mu \mathrm{l}$ water. The debris were removed by centrifugation $\left(2,000 \mathrm{~g}, 4{ }^{\circ} \mathrm{C}, 10 \mathrm{~min}\right)$ and the supernatant was filtered on $0.22 \mu \mathrm{m}$ (Millipore Millex-GV $13 \mathrm{~mm}$ ). The filter was further washed with $700 \mu 180 / 20$ acetonitrile containing $10 \mathrm{mM}$ ammonium carbonate ( $\mathrm{pH}$ adjusted to 9.9 with $\mathrm{NH}_{4} \mathrm{OH}$ ). The resulting $1 \mathrm{ml}$ samples were stored at $4{ }^{\circ} \mathrm{C}$ and analyzed within $24 \mathrm{~h}$.

\subsubsection{Chromatographic conditions}

Analyses were conducted using an Accela LC system (Thermo Fisher Scientific, Courtaboeuf, France) with two different chromatographic columns. Chromatographic separation using an Acquity $^{\circledR} \mathrm{C} 18$ column $(150 \times$ $2.1 \mathrm{~mm}^{2}$; $1.7 \mu \mathrm{m}$; Waters) was carried out at $50{ }^{\circ} \mathrm{C}$ as follow: a mobile phase gradient was used with a flow rate of $0.4 \mathrm{ml} / \mathrm{min}$ in which mobile phase A consisted of 
$10 \mathrm{mM}$ ammonium acetate with $\mathrm{pH}$ adjusted to 3.5 with $0.1 \%$ ( $\mathrm{vol} / \mathrm{vol})$ formic acid and mobile phase B consisted of methanol. The gradient started at $100 \% \mathrm{~A}$ for $1 \mathrm{~min}$, followed by a linear gradient at $100 \% \mathrm{~B}$ for $9 \mathrm{~min}$, and remained $8 \mathrm{~min}$ at $100 \% \mathrm{~B}$. The system returned to the initial solvent composition in $2 \mathrm{~min}$ and re-equilibrated under these conditions for $5 \mathrm{~min}$. Elution from a $\mathrm{ZIC}^{\circledR}$ $p$ HILIC column $\left(150 \times 4.6 \mathrm{~mm}^{2} ; 5 \mu \mathrm{m}\right.$; Merck Sequant $)$ was conducted at $40{ }^{\circ} \mathrm{C}$ using a mobile phase gradient with a flow rate of $0.5 \mathrm{ml} / \mathrm{min}$. A consisted of $10 \mathrm{mM}$ ammonium carbonate with $\mathrm{pH}$ adjusted to 9.9 with $\mathrm{NH}_{4} \mathrm{OH}$ and $\mathrm{B}$ of acetonitrile. The gradient started at $80 \% \mathrm{~B}$ for $2 \mathrm{~min}$, followed by a linear gradient to $40 \% \mathrm{~B}$ at $22 \mathrm{~min}$ and remained $8 \mathrm{~min}$ at $40 \% \mathrm{~B}$. The system returned to the initial solvent composition in $5 \mathrm{~min}$ and re-equilibrated under these conditions for $15 \mathrm{~min}$. For each chromatographic method, the autosampler was kept at $4{ }^{\circ} \mathrm{C}$ and $10 \mu \mathrm{l}$ were injected.

\subsubsection{LTQ-Orbitrap analysis}

High-resolution measurements were obtained with a LTQOrbitrap mass spectrometer (Thermo Fisher Scientific) fitted with a heated electrospray ionisation source (HESI) operating in positive and negative ionization modes. In the positive ion mode, the electrospray voltage was set to $4.5 \mathrm{kV}$, the capillary voltage to $48 \mathrm{~V}$, and the tube lens offset to $80 \mathrm{~V}$. The sheath and auxiliary gas flows (both nitrogen) were respectively optimized at 60 and 50 (arbitrary units), and the drying gas temperature was set to $275^{\circ} \mathrm{C}$. The same settings were used for the negative ion mode, except for the electrospray voltage, which was fixed at $4 \mathrm{kV}$, and the capillary voltage and tube lens offset, which were set to -30 and $-90 \mathrm{~V}$, respectively. Mass spectra were acquired over an $\mathrm{m} / \mathrm{z}$ range from $m / z, 50$ up to $m / z, 1000$ with the mass resolution set to $30,000 \mathrm{FWHM}$ at $\mathrm{m} / \mathrm{z}, 400$ in the Orbitrap analyzer. Collision-induced dissociation spectra (CID) in resonant excitation conditions were acquired using data-dependent scanning function for identification purpose. Target gas for CID was helium. The scan event cycle comprised a mass spectrum at a resolution power of 30,000 and data-dependent $\left(\mathrm{MS}^{2}\right)$ events acquired with the ion trap. Microscan count was set to unity and a repeat count for dynamic exclusion was set to $3 . \mathrm{MS}^{\mathrm{n}}$ acquisition parameters were an isolation width of $\mathrm{m} / \mathrm{z} 1$, normalized collision energy at $35 \%$, and an activation time of $30 \mathrm{~ms}$.

\subsubsection{Preparation of standards and calibration solutions}

Commercial metabolite standards were prepared for each analytical run from a $0.1 \mathrm{M}$ solution in water stored at $-20{ }^{\circ} \mathrm{C}$ and diluted to $50 \mu \mathrm{M}$ in $80 / 20$ acetonitrile/ ammonium carbonate $\mathrm{pH} 9.9$ for $\mathrm{ZIC}^{\circledR}-p \mathrm{HILIC}$ analysis and in 80/20 ammonium acetate $\mathrm{pH} 3.5 /$ methanol for $\mathrm{C} 18$ analysis. For ZIC ${ }^{\circledR}-p$ HILIC analysis, calibration curves of AMP, ADP and ATP were required to calculate the Adenylate Energy Charge (see below); we prepared calibration solutions with concentrations of $0.1,0.5,1,2.5,5$, 7.5, $10 \mu \mathrm{M}$ for AMP and ADP and with concentrations of $2,5,10,15,20 \mu \mathrm{M}$ for ATP in $30 \%$ water and $70 \%$ mobile phase containing 80/20 acetonitrile/ammonium carbonate $\mathrm{pH}$ 9.9. Calibration curves were done in positive ionization mode (Online Resource 2, Table S-2). The matrix effect on the AEC calculation in ADP1 metabolomic samples was investigated. The use of ${ }^{15} \mathrm{~N}$ labelled nucleotides revealed only a slight underestimation of the AEC (data not shown).

\subsubsection{Metabolomic data processing}

LC/MS data were acquired in raw files and processed with the Qualbrowser module of Xcalibur 2.2 (Thermo Fisher Scientific) to access to elemental compositions. 2 biological replicates originating from the same quinate cultures day (Online Resource 1, Figure S-1) were removed from the data set due to technical problems. This led to a reduced data set consisting of 6 and 4 metabolomes originating from succinate- and quinate-grown cells, respectively. Each metabolome was injected twice and considered as analytical replicates. This data set was thus used as the raw data for data pretreatment. For global analysis, raw data files were converted into the mzXML format using the MassMatrix File Conversion Tools (http://www.massma trix.net). Data were analyzed by the web-based platform XCMS Online (Tautenhahn et al. 2012) version 1.22.01. The centWave algorithm (Tautenhahn et al. 2008) was used. The parametring of XCMS was conducted in both ionization modes with a mixture of 126 commercial compounds representative of the metabolism, at a concentration of $50 \mu \mathrm{M}$ each. Out of them, 119 were detected in the RAW data (not shown). We first used HPLC/Orbitrap II default settings and adjusted empirically the parameters to optimize the detection of the standards. The parameters that were tuned were ppm, max peakwidth, prefilter intensity, noise filter, and minfrac, which were respectively set at $3,45,100,0$, and $0.75 . S / N$ threshold was set at 6 and 3 for the positive and negative ionization modes, respectively. Using this parametring, 117 out of the 119 standards detected in the RAW files could be identified by XCMS (although 7 were poorly detected). This refined parametring was used to process the ADP1 metabolomic data. Redundant ion signals (natural isotopes, adduct ions, dimer ions and fragment ions) were automatically annotated and combined in different feature groups of related peaks, each group corresponding to one potential metabolite. A final data set was defined after manual verification in the raw 
data of each peak detected by XCMS, in both ionization modes, to remove ions also present in the medium culture, misintegrated peaks, and all redundant information. The analytical reproducibility was determined by establishing the relative standard deviation (RSD) between the analytical replicates. The biological reproducibility, i.e. the variability of the concentration of a specific metabolite as determined in ADP1 cells grown under identical conditions in independent cultures, was also estimated by the RSD. When biological RSD calculations were $\geq 40 \%$, peaks area were manually verified and corrected, especially for peaks close to the detection limit. The selected mass chromatograms were putatively identified by matching the masses (mass accuracy $<10 \mathrm{ppm}$ ) to those from public databases (KEGG and Metlin). Metabolite identification was aided by $\mathrm{MS}^{\mathrm{n}}$ interpretation and retention time matching to commercial reference standards.

The concentration of a metabolite was considered as increased relative to succinate if it increased at least threefold in signal intensity $(P<0.05)$. Conversely, the concentration of a metabolite was considered as decreased for a reduction in signal intensity of at least threefold $(P<0.05)$. Using the $\mathrm{R}$ package Muma (Gaude et al. 2013), the final data set was first mean-centered, reduced and scaled to Pareto variance to perform principal component analysis (PCA).

\subsubsection{Metabolite identification}

Metabolites extracted from ADP1 were identified by comparison of the retention time, $m / z$ ratio and $\mathrm{MS}^{\mathrm{n}}$ spectra with those of authentic reference compounds, when available, from our in-house chemical library and from the one kindly provided by Dr. Christophe Junot.

\section{Results and discussion}

As cell cultures for RNA-seq analysis were conducted in liquid medium, and those for metabolome extraction on solid medium (see Sects. 2, 2.5.1), growth kinetics in liquid medium and in filter cultures (with $\mathrm{OD}_{600}$ measurements done every $30 \mathrm{~min}$ ) were conducted and compared. Results indicated that the growth behavior of ADP1 was similar in the two conditions (data not shown).

\subsection{RNA_seq analysis}

\subsubsection{Quinate triggered a large scale transcriptional reorganization}

High-throughput sequencing of cDNA prepared from RNA, a methodology known as RNA-seq, has become the method of choice for genome-wide transcriptome analyses, with unprecedented sensitivity and dynamic range (Wang et al. 2009; Wilhelm et al. 2010). Here, directional RNA sequencing libraries were prepared in duplicates from succinate and quinate-grown cells. A summary of the outcome of these experiments is presented in Online Resource 1, Table S-3. After mapping the reads on ADP1 genome sequence, data analysis yielded the relative expression level for 3,303 genes (Online Resource 2, Table S-4). The comparative analysis revealed that shifting the carbon source from succinate to quinate did not merely lead to the up-regulation of the genes implicated in the degradation of quinate, but altered the global transcription pattern of the cell (Fig. 2). More than 400 genes of different functional classes were affected, with an equivalent proportion of genes up- and down-regulated. Up-regulated genes mostly coded for enzymes (100), ribosomal proteins (25), proteins of unknown function (23) and proteins known to be involved in stress conditions (DnaK, DnaJ, GroES, GroEL, HslO, HtpG...). But the most unexpected observation was that the large majority of down-regulated genes were ORFs of unknown function (133). For most of them, their transcription status was not affected during heat shock at $42{ }^{\circ} \mathrm{C}$ (de Berardinis V., personal communication). It was reported that changing the nutritional regime of a bacterium could affect gene regulation (Klumpp et al. 2009). In particular, the number of genes differentially expressed increased as the quality of the carbon source declined (defined by the value of the growth rate). It can represent up to $\sim 7 \%$ (292 genes with a fold change $\geq 3$ ) of the total number of genes in E. coli (Liu et al. 2005) and up to $\sim 18 \%(1,024$ genes with a fold change $\geq 2)$ in Pseudomonas putida (Kim et al. 2013). For ADP1, both carbon sources used in this study were of similar quality, as succinate led to a growth rate of $0.84 \pm 0.03 \mathrm{~h}^{-1}$ and quinate $0.79 \pm 0.01 \mathrm{~h}^{-1}$ (values correspond to the average and standard deviation of three independent experiments). While in P. putida the use of carbon sources of similar quality affected $\sim 6 \%$ (325 genes with a fold change $\geq 2$ ) of the genes (Kim et al. 2013), here, $\sim 12 \%$ (415 genes with a fold change $\geq 3)$ or $\sim 30 \%(1,086$ genes with a fold change $\geq 2$ ) of the genes were affected. In conclusion, our data indicate that quinate elicited not only a specific transcriptional response that allowed quinate dissimilation, but also a global transcriptional response that was independent of the growth rate of the cell.

\subsubsection{Regulation of the protocatechuate branch of the $\beta$ - ketoadipate pathway}

As anticipated, the 14 genes known to participate in quinate degradation were among the most up-regulated (Fig. 1; Online Resource 2, Table S-4), further confirming 
Fig. 2 Number and functional classification of genes differentially expressed in $A$. baylyi ADP1 grown on quinate as compared with succinate. Each plot indicates the type of physiological role(s) and the total number of genes with increased or decreased expression within that category in cells grown on quinate (see also Online Resource 2, Table S-4)

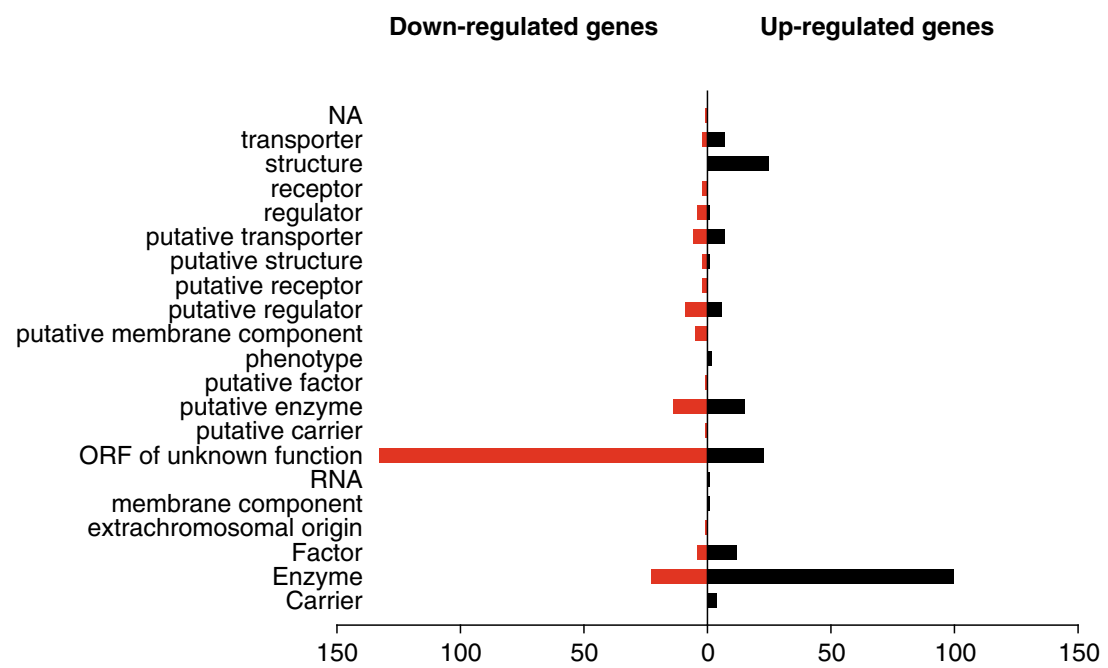

that the protocatechuate branch of the $\beta$-ketoadipate pathway has to be induced for quinate dissimilation. The high expression level of the $p c a$ and qui genes observed here is consistent with an operonic organization of the pcaI-quiA region (Dal et al. 2005), and the carbon source-dependent regulation of pcaU expression observed here (13-fold) is also in agreement with previous results (Siehler et al. 2007). The protocatechuate branch of the $\beta$-ketoadipate pathway is under the transcriptional control of the activators-repressors PcaU and PobR. PcaU controls two promoters facing in opposite directions: the promoter for its own expression and the one for the expression of the first structural gene pcaI (Online Resource 1, Figure S-2A). PobR responds to $p$-hydroxybenzoate and activates the transcription of pobA, coding for the enzyme that converts $p$-hydroxybenzoate to protocatechuate. This latter triggers in turn the action of PcaU. Earlier studies indicated that $p$-hydroxybenzoate degradation is inhibited if an additional aromatic carbon source is present in the medium (Brzostowicz et al. 2003). In particular, the $\beta$-galactosidase activity of the fusion pobA::lacZ was negligible when quinate was the carbon source, suggesting that pobA expression was repressed (Brzostowicz et al. 2003; DiMarco et al. 1993). Here, pobA is up-regulated 29-fold, suggesting that the low $\beta$-galactosidase activity observed by Brzostowicz et al. may be caused by a post-transcriptional event (RNA degradation, etc.) rather than the inhibition of $p o b A$ transcription per se.

\subsubsection{Genes next to IclR-type regulators were up-regulated during growth on quinate}

The binding, at least partially, of PcaU (that belongs to the IclR family) on the binding site of other IclR proteins on the genome may explain why some genes were up-regulated. Six other IclR-type proteins were identified by
Gerischer et al. in ADP1 (Gerischer et al. 2008). Their function remains unknown but as in many cases the target of a transcriptional regulator is very close to the regulator gene, we inspected the transcription status of their neighbor genes. Results reported in Table 1 indicated that for 5 out of the 6 genes encoding IclR-type proteins, their neighboring genes were indeed up-regulated. Out of them, the cluster ACIAD0349-0351 is composed of genes highly conserved in proteobacteria. ACIAD0350 contains a domain of unknown function (DUF1656) also present in a cluster of three genes in $E$. coli that form an efflux pump (named AaeXAB). It has been proposed that AaeXAB excretes $p$-hydroxybenzoate when its intracellular concentration is abnormally high (Van Dyk et al. 2004). Members of the same DUF can have different enzymatic reactions but be highly related in their catalytic mechanism (Bastard et al. 2013), thus it cannot be ruled out that AaeXAB and the cluster ACIAD0349-0351 are related in their function. On the other hand, Gerischer et al. also identified 20 putative IclR regulator binding sites in the genome, with 6 located in intergenic regions, making them the most likely candidates for regulator binding (Gerischer et al. 2008). Out of them, 4 were located in the intergenic regions in between pcaU-pcaI on one side, and pobR-pobA on the other side. But regarding the 2 remaining putative sites, one is located next to a cluster of 5 genes involved in the synthesis of PQQ (ACIAD2503-2507), which are essential for growth on quinate (de Berardinis et al. 2008). Gerischer et al. speculated that the $p q q$ cluster could be, at least partially, influenced by the binding of PcaU. RNA-seq data showed that 4 out of the 5 PQQ genes were up-regulated (Table 1). The last putative binding site is located between van $K$ and $v a n A / B$ (Table 1$)$. On the one hand, it was suggested that vanK, whose product has overlapping specificities with PcaK, is also induced by protocatechuate in ADP1 (D'Argenio et al. 1999). The authors also pointed 
Table 1 ADP1 genes putatively regulated by IClR-type regulators

\begin{tabular}{|c|c|c|c|}
\hline ADP1 gene & Description & Neighboring genes & Up-regulation (fold) \\
\hline \multirow[t]{3}{*}{ ACIAD0347 } & \multirow[t]{3}{*}{ Putative transcriptional regulator } & ACIAD0349 (CHP) & $\times 34$ \\
\hline & & ACIAD0350 (CHP) & $\times 10$ \\
\hline & & ACIAD0351(CHP) & $\times 13$ \\
\hline ACIAD1684 (dcaS) & Putative transcriptional regulator & ACIAD1687 (caiB) & $\times 4$ \\
\hline \multirow[t]{3}{*}{ ACIAD1688 (dcaR) } & \multirow[t]{3}{*}{ Putative transcriptional regulator } & ACIAD1689 (dcaF) & $\times 4$ \\
\hline & & ACIAD1690 (dcaH) & $\times 3$ \\
\hline & & ACIAD1691 (dcaC) & $\times 4$ \\
\hline \multirow[t]{4}{*}{ ACIAD1822 } & \multirow[t]{4}{*}{ Putative transcriptional regulator } & ACIAD1827 & $\times 3$ \\
\hline & & ACIAD1828 & $\times 4$ \\
\hline & & ACIAD1829 & $\times 3$ \\
\hline & & ACIAD1830 & $\times 4$ \\
\hline \multirow[t]{3}{*}{ ACIAD0985 ( $p c a U$-like) } & \multirow[t]{3}{*}{ Putative transcriptional regulator } & ACIAD0979 (vanB) & $\times 4$ \\
\hline & & ACIAD0980 (vanA) & $\times 4$ \\
\hline & & ACIAD0984 (salA-like) & $\times 4$ \\
\hline $\begin{array}{l}\text { Intergenic sequences in ADP1 genome } \\
\text { with similarity to PcaU/PobR binding sites }\end{array}$ & ATG distance & Neighboring genes & Up-regulation (fold) \\
\hline \multirow[t]{5}{*}{ Start:245976 end:2459992 } & \multirow[t]{5}{*}{$94(p q q A)$} & ACIAD2503 (pqqA) & $\times 2$ \\
\hline & & ACIAD2504 (pqqB) & $\times 5$ \\
\hline & & ACIAD2505 (pqqC) & $\times 4$ \\
\hline & & ACIAD2506 (pqqD) & $\times 3$ \\
\hline & & ACIAD2507 (pqqE) & $\times 4$ \\
\hline \multirow[t]{2}{*}{ Start:968161 end:968177 } & \multirow[t]{2}{*}{$206($ vanK $)$} & ACIAD0982 (vanK) & $\times 28$ \\
\hline & & ACIAD0983 (vanP) & $\times 30$ \\
\hline
\end{tabular}

out that this metabolite may also induce expression of vanA and $v a n B$. On the other hand, it was speculated that a IclR protein targets this binding site and effects the expression of vanK,P and/or vanA,B (Gerischer et al. 2008). Data presented here conciliate these two hypotheses and suggest that ACIAD0985 (pcaU-like) is involved in the transcription of $v a n A B$.

\subsubsection{Regulation of genes of the catechol branch of the $\beta$ - ketoadipate pathway}

The expression of the genes required for catechol and protocatechuate degradation, respectively, is regulated independently (Fischer et al. 2008), cis,cis-muconate being the major inducer of the catechol branch (Bundy et al. 2002) (Brzostowicz et al. 2003). Thus, the genes involved in the degradation of substrates feeding into the catechol branch were not expected to be up-regulated in cells grown with quinate as the sole carbon source. Surprisingly, many genes were indeed up-regulated. This was the case for the are $C B A$ genes, which are necessary for growth on benzyl alkanoates (Fig. 1; Online Resource 2, Table S-4). areCBA was suggested to be an operon induced by aromatic compounds as benzyl acetate, benzyl alcohol, and benzaldehyde (Jones and Williams 2001). Next, the salED genes, located close to the areCBA operon (Online Resource 1,
Figure S-2B), were also up-regulated (Fig. 1; Online Resource 2, Table S-4). salED and salAR, which metabolize salicylate and salicylate esters, were proposed to be organized into two convergent transcription units in ADP1 (Jones et al. 2000). The authors hypothesized that salDE could be cotranscribed with are $C B A$. Consistent with this hypothesis, RNA-seq data showed that salED and are $C B A$ were up-regulated while the transcription of salAR remained unchanged. Nevertheless, the up-regulation for these genes has never been reported in the absence of the substrates of their encoded enzymes. Finally, in the same catabolic island the cat genes involved in catechol degradation are organized in two transcriptional units: $c a t A$ on the one hand and the catBCIJFD operon on the other hand (Romero-Arroyo et al. 1995). Here, catA was up-regulated (Fig. 1; Online Resource 2, Table S-4), despite the absence in the culture medium of any aromatic compound that could be degraded into the inducer cis, cis-muconate.

\subsection{Metabolomics}

\subsubsection{Selection of the chromatographic conditions}

To analyze the metabolome of ADP1, we aimed to set up an efficient liquid chromatography method for the separation of the metabolites prior to their detection by high-resolution 
mass spectrometry. The chromatographic separation step is critical to limit ion suppression effects (King et al. 2000; Taylor 2005). We focused on the detection of the intermediates of the central carbon metabolism, i.e. polar metabolites, and on the quantification of AMP, ADP, and ATP, to estimate the energy charge of the cell (see below). A first chromatographic method took advantage of the widely used C18-UHPLC technology. Alternatively, the more recent ZIC-pHILIC column was evaluated, as hydrophilic interaction liquid chromatography has recently been successfully used in metabolomic studies (Kamleh et al. 2008; Nguyen and Schug 2008; t'Kindt et al. 2010). AMP, ADP and ATP eluted from the ZIC- $p$ HILIC column at $\sim 11,13$ and $15 \mathrm{~min}$, respectively, with an asymmetry factor close to 1 (not shown), allowing quantification in biological samples. It is worthy to note that such values for these 3 nucleotides could only be obtained with a $\mathrm{pH}$ value of 9.9 for the aqueous mobile phase. On the opposite, with the C18 column, AMP, ADP and ATP were poorly retained $(<2 \mathrm{~min})$ with an asymmetry factor $>2$, impeding quantification. Such a lack of retention on a $\mathrm{C} 18$ column has been previously reported (Coulier et al. 2006). To further compare the retention and separation properties of the two chromatographic columns, 121 commercial compounds representative of the diversity of the metabolism were analyzed in both positive and negative ionization modes (Online Resource 1, Table S-5). These reference metabolites ranged from $\mathrm{m} / \mathrm{z}$ values of 68 to 809 , and comprised amino acids, amino acids precursors or derivatives, nucleosides, nucleotides, organic acids, vitamins and derivatives, and redox electron carriers. Eight of these compounds could not be detected on at least one column, but more than $95 \%$ were retained on the ZIC- $p$ HILIC column and only $\sim 20 \%$ on the $\mathrm{C} 18$ column (Online Resource 1, Figure S-3). In conclusion, all metabolomics investigations were conducted with the ZIC- $p$ HILIC column.

\subsubsection{Reproducibility of metabolomics sampling}

We intended to investigate the metabolism of exponentially growing cells of ADP1 through representative metabolome preparations, in which the metabolome composition has to be as close as possible to the metabolite content of the cultured cells at the moment of sampling. As metabolites can have a lifetime of seconds and even less for ATP (Walsh and Koshland 1984), this required rapid cell quenching combined with cell inactivation to 'freeze' the microbial metabolism. To evaluate the quality of metabolism quenching, along with the extraction and analytical methods employed, we calculated the adenylate energy charge (AEC) i.e. the amount of metabolically available energy of the cells, according to the formula proposed by (Chapman et al. 1971),

$$
\mathrm{AEC}=\frac{[A T P]+0.5[A D P]}{([A T P]+[A D P]+[A M P])} .
$$

The AEC values obtained from the same carbon source were highly reproducible. A value of $0.84 \pm 0.01$ was obtained for cells grown on succinate, which is consistent with the one proposed by Chapman et al. for cells of $E$. coli during normal growth (Chapman et al. 1971). Surprisingly, quinate-grown cells displayed a lower value of $0.66 \pm 0.08$. The reproducibility of this value indicated that it was probably not related with an incorrect handling of the cells during sampling and LC/MS analysis, but rather a characteristic of growth on quinate. It is also ruled out that the cells entered a starvation phase during their cultivation. Studies have shown that the level of global negative supercoiling of chromosomal DNA is controlled by the cellular energy charge (Higgins et al. 1988; Hsieh et al. 1991). A variation of the AEC, in response of environmental conditions, can trigger a change of DNA superhelicity, affecting the entire chromosome and the expression levels of all operons whose promoters are sensitive to superhelicity. Hatfield and Benham proposed that, in this way, the global pattern of gene expression may be dynamically tuned to changing needs of the cell under a wide variety of circumstances (Hatfield and Benham 2002). Thus, the global transcriptional response elicited by quinate in ADP1 may be linked to the energy charge instead of the growth rate. Alternatively, it cannot be excluded that quinate is a substrate that does not obey the hypothesis that gene expression depends directly on bacterial growth (Klumpp et al. 2009).

\subsubsection{Global analysis of the metabolome}

3.2.3.1 Data processing XCMS automatic peak detection yielded 1,258 peaks in positive ionization mode and 1,574 in negative ionization mode, classified in 227 and 356 feature groups, respectively. Data were further examined to remove non-relevant peaks and incorrect datagathering, leading to a final list of 451 validated metabolites: 280 in positive ionization mode, 171 in negative ionization mode, and 38 in both ionization modes (Online Resource 2, Table S-6). 352 could be matched to known compounds querying metabolic databases (Kegg and/or Metlin) and 99 remained without any proposition. The retention time, accurate mass, and CID spectrum profile when available (low mass cut-off of fragmentations or low signal intensity being limiting factors) of the putatively identified metabolites were compared to those of commercial standards. Finally, 105 metabolites could be identified with high confidence according to the Metabolomics Standards Initiative (Sumner et al. 2007) (Online Resource 2 , Table S-7). The quality of data processing by XCMS is 
illustrated in Online Resource 1, Figure S-4 for one metabolite representative of run to run retention time drift (alanine; M90T682) and in Figure S-5 for one metabolite characteristic of a low abundant species (cytosine; M112T459). We used a PCA to visualize the structuring of our final data set, and found that all samples corresponding to the same growth condition grouped together (Online Resource 1, Figure S-6), illustrating the robustness of our data. The clear separation between the 2 groups showed that the nutritional regime is the main parameter differentiating the metabolomes. The reproducibility of our sample preparation was further confirmed by the RSD values calculated from biological replicates $(<40 \%)$ for each carbon source, all being consistent with published data (Bajad et al. 2006; Fiehn et al. 2000; van der Werf et al. 2008).

\subsubsection{Metabolome overview The concerted effects of} changes in gene expression due to changes in the environment, observed through RNA-seq data, should be ultimately reflected in the metabolome. This was actually the case, as Fig. 3 shows that the metabolome was dramatically affected. Metabolites eluted along the whole chromatographic gradient and ranged from $\mathrm{m} / \mathrm{z} 62$ to 955 , illustrating their great chemical and structural diversities. They were more concentrated in quinate-grown cells, with numerous molecules accumulating more than tenfold. 227 metabolites had their concentration modified, indicating that $\sim 50 \%$ of LC/MS-detected metabolites were affected by the carbon source. For those whose concentration was most affected and which were more abundant in quinategrown cells, some could not be matched to metabolic databases. For the ones that matched to databases, most of the proposed identities did not correspond to expected metabolites for ADP1 and have therefore to be further verified experimentally. A first hypothesis could be that for some of them, identities are indeed correct, these metabolites being unpredicted in ADP1. Alternatively, proposed identities could be wrong because the structure of some of these metabolites has not been reported so far. In both cases, these metabolites would represent an unknown side of ADP1 metabolism. Determining their identity would thus be a priority.

Concerning the 105 identified metabolites, their distribution pattern, presented in Fig. 4, also shows that more metabolites accumulated during growth on quinate. More than 70 belonged to metabolic pathways related to central metabolism (metabolism of amino acids, nucleotides, and TCA cycle), and for most of them, their concentration was not affected by the carbon source. This suggests that the central metabolism of ADP1 was independent of the nature of the carbon source, which is in agreement with reports on related organisms (Frimmersdorf et al. 2010; van der Werf et al. 2008). Nevertheless, out of these 105 metabolites identified, 41 had their concentration affected by the carbon source shift. These included the expected catabolic intermediates of quinate degradation that accumulated in quinate-grown cells, as protocatechuate, 3-oxoadipate, dehydroquinate, and dehydroshikimate. 3-Carboxy-cis, cismuconate acid was also detected, its fragmentation pattern being consistent with its structure (Online Resource 1, Figure S-7). These results agreed with RNA-seq data showing that all the known genes involved in quinate degradation were highly up-regulated. But metabolites not related to quinate catabolism had their concentration affected as well.
Fig. 3 Visualization of the 451 LC/MS-detected metabolites of A. baylyi ADP1. The retention time on the ZIC- $p$ HILIC column is represented by position on the $x$-axis. Mass-tocharge ratio is represented by position on the $y$-axis. Fold change is indicated by color and radius of each metabolite (log scale). Upper panels metabolites accumulating in quinate-grown cells. Lower panels metabolites accumulating in succinategrown cells

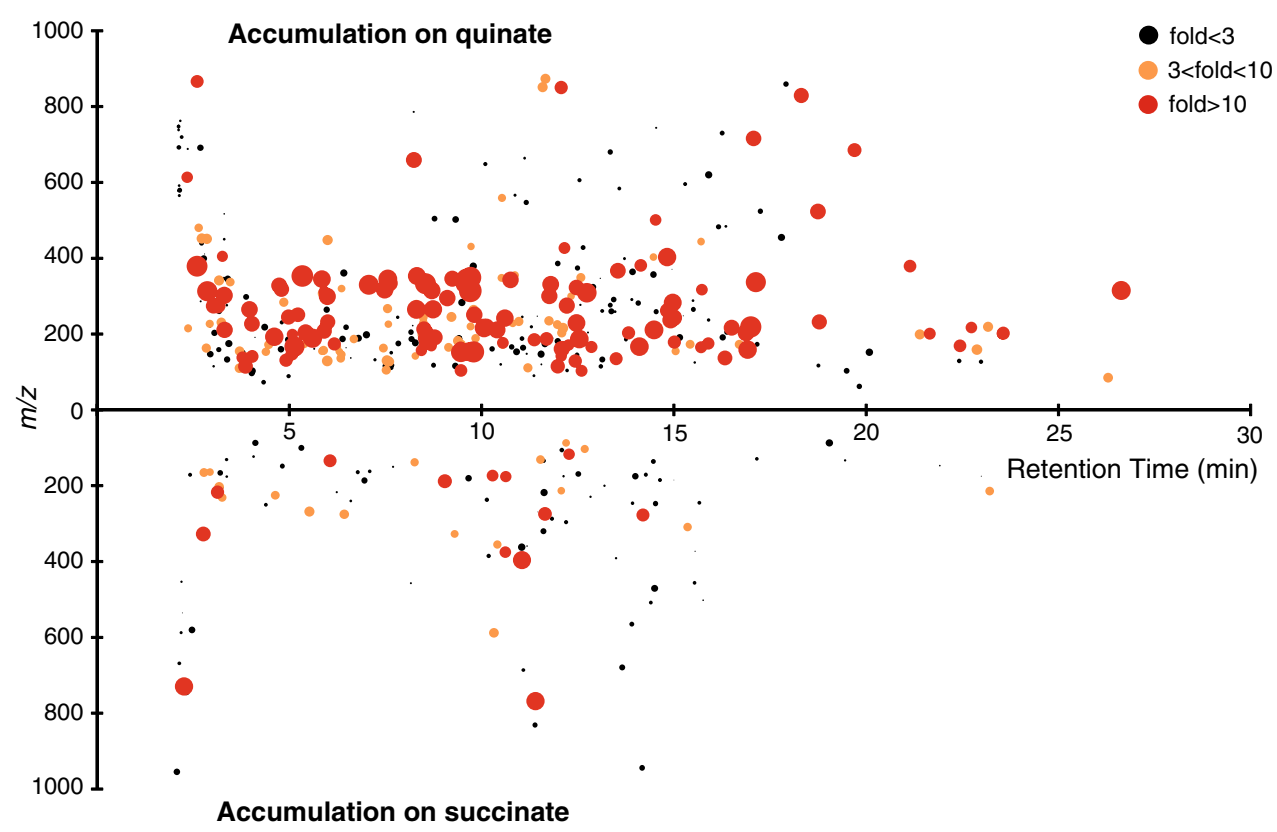




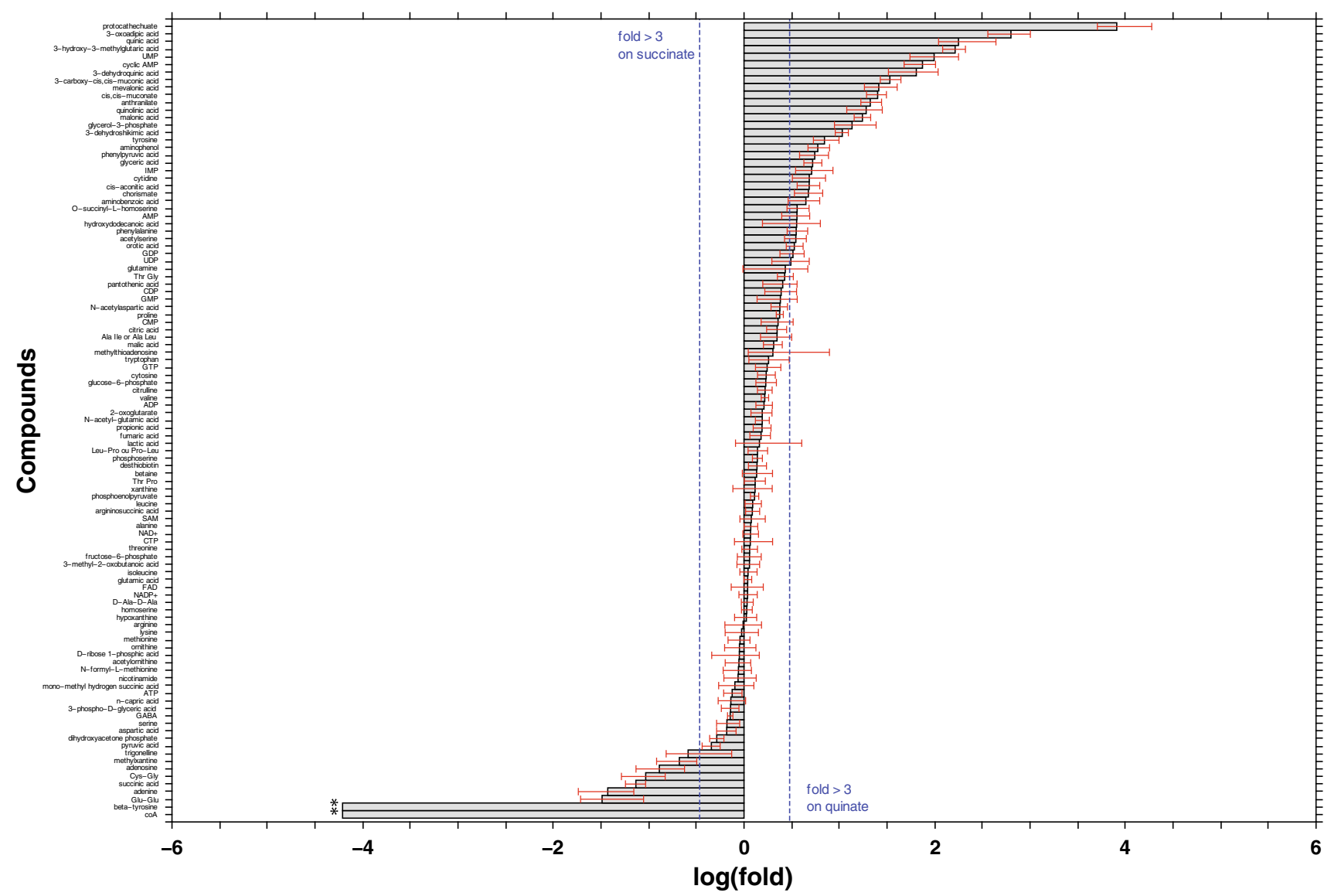

Fig. 4 Differences for identified metabolites in ADP1 metabolomes. Alterations are expressed as $\log$ (fold). The confidence intervals of $\log$ (fold) at $95 \%$ (red whiskers) were determined using Fieller's formula (Fieller 1954) derived from the $t$ test for the ratio of two means with unequal variances (Tamhane and Logan 2004). Data represent the average for 6 independent succinate metabolomes and 4 quinate metabolomes. Dotted blue lines correspond to a fold-change of 3. Asterisk indicates metabolites for which the fold-change is infinite (absence in quinate-grown cells) (Color figure online)

accumulation of the two aromatic amino acids and their precursors could be caused by a leak, from periplasm to cytoplasm of metabolites that are common to both quinate degradation and shikimate synthesis, such as 3-dehydroquinate and/or 3-dehydroshikimate. This unsuspected transport, which could involve VanK and/or PcaK would in turn enhance the biosynthetic flux of aromatic amino acids, leading to their accumulation in the cell. ACIAD3353, coding for 3-dehydroquinate synthase (EC 4.2.3.4) and ACIAD1738, coding for 3-dehydroquinate dehydratase (EC 4.2.1.10) are obligatory genes involved in the synthesis of the anabolic 3-dehydroquinate and 3-dehydroshikimate. The deletion of either ACIAD3353 or ACIAD1738 is lethal for cells grown on succinate (de Berardinis et al. 2008). According to our alternative hypothesis, their deletion should not impede cell growth if quinate is the carbon source, the disruption of the normal biosynthetic pathway being complemented by transport in the cytoplasm of catabolic 3-dehydroquinate and 3-dehydroshikimate for aromatic amino acid synthesis. Hence, 
the 2 deletion mutants ( $\triangle \mathrm{ACIAD} 3353$ and $\triangle \mathrm{ACIAD} 1738$ ) were constructed. Clones for each mutant were first selected on plates of MA medium containing succinate as the carbon source, and supplemented with kanamycin to select $\mathrm{Kan}^{\mathrm{R}}$ colonies and shikimate to allow aromatic amino acid biosynthesis. For both mutants, succinategrown cells were auxotroph for shikimate while quinategrown ones remained prototroph (Online Resource 1, Table $\mathrm{S}-8)$. These results indicate that when quinate is metabolized, a flux of 3-dehydroshikimate crosses the cytoplasmic membrane and feeds into the aromatic amino acid pathway. Further studies would be required to explain the unaffected concentration of tryptophan.

\subsubsection{Identified metabolites were not predicted by ADP1} genome-scale metabolic model We previously reported on the construction of a constraint-based metabolic model of ADP1, iAbaylyiv4 (Durot et al. 2008). Genome-scale metabolic models are powerful tools to study global properties of metabolic networks. This model allowed generating in silico metabolites, according to the carbon source used (not shown). We observed that some of the metabolites experimentally identified in the metabolomes of ADP1 were actually not predicted by the model for quinate- and/or succinate-grown cells. For example, $\gamma$-aminobutyrate (GABA, Online Resource 2, Table S-7 and Online Resource 1, Figure S-8) is not proposed by iAbaylyiv4: while gabT (ACIAD3446) and gabD (ACIAD3445), involved in the conversion of GABA to succinate are identified, the annotation of a gene encoding a GABA producing glutamate decarboxylase is missing. It was previously observed that the genes coding for the E1 and E2 components of the 2-oxoglutarate dehydrogenase complex, sucA (ACIAD2876) and $s u c B$ (ACIAD2875), were not essential (de Berardinis et al. 2008), although their deletion, disrupting the TCA cycle, should be lethal. The identification of GABA in ADP1 metabolome supports the hypothesis that a nonidentified glutamate decarboxylase helps in succinate formation from 2-oxoglutarate through the GABA shunt. Malonate (Online Resource 1, Figure S-9) and 3-hydroxy-3methylglutarate (Online Resource 1, Figure S-10) could be the hydrolysis products of the corresponding Coenzyme A esters in the chromatographic mobile phase, as these compounds are unstable at alkaline $\mathrm{pH}$ (Joyard and Stumpf 1980). However, these compounds gave clearly defined peaks (not shown) while hydrolysis products would give tailing peaks since it would not be instantaneous. While malonyl-CoA is an obligate intermediate in fatty acids synthesis, 3-hydroxy-3-methylglutaryl-CoA is not expected, but ADP1 contains a putative hydroxymethylglutaryl-CoA lyase (ACIAD2820) that could metabolize it into 3-hydroxy-3-methylglutarate. 3-hydroxy-3-methylglutarylCoA also belongs to the mevalonate pathway for terpenoid biosynthesis, which is not either predicted to occur in ADP1 (Barbe et al. 2004). Nevertheless, it is noteworthy that mevalonate was also potentially identified in the metabolome (Online Resource 2, Table S-7 and Online Resource 1, Figure S-11) and that 3-hydroxy-3-methylglutarate and mevalonate both accumulated in quinate-growth conditions (164-fold and 26-fold, respectively), suggesting that they could be related. $N$-acetylaspartate, mono-methyl hydrogen succinate, and trigonelline were also identified (Online Resource 2, Table S-7 and Online Resource 1, Figures S-12, $13,14)$ although, to our knowledge, these compounds have never been reported to occur in bacteria so far. We could putatively identify cis-cis muconate comparing its fragmentation pattern to the one of its counterpart in the protocatechuate branch, 3-carboxy-cis,cis-muconate. This compound, known only as a catabolite of the catechol branch was not expected either (Online Resource 1, Figure S-7).

Finally, $\sim 15 \%(16 / 105)$ of the metabolites experimentally identified in ADP1 metabolome were not predicted by iAbaylyiv4 model. Although there is continuous progress on integrating omics analyses in metabolic models, the modeling of metabolic networks remains simplified and limited (Oh et al. 2007). This is mostly due to the fact that many reactions that play part in metabolism have not been studied. At the present time, the annotation of the ADP1 genome is incomplete, and $\sim 30 \%$ of the genes are still annotated as ORFs of unknown function. Therefore, our genome-scale model obviously lack metabolic capabilities that ADP1 possesses.

To conclude, 28 unidentified compounds were present exclusively in quinate-grown cells (Online Resource 2, Table S-6). None of them could be identified and moreover, for 18 of them no putative identity could be assigned by Kegg database. Thus, data suggest that during the global transcriptional response triggered by quinate, unsuspected enzymatic activities took place and led to the formation of unknown metabolites that are not related to the current knowledge of the quinate dissimilation pathway. In other words, this study, that integrated transcriptomic and metabolomic approaches, gave indication that all the enzymatic reactions and metabolic pathways in ADP1 have not yet been identified.

\subsection{Growth phenotyping of ADP1 collection of deletion mutants}

To identify the genes participating in the catabolism of quinate, our laboratory previously conducted the profiling for growth on quinate of the whole collection of deletion mutants (de Berardinis et al. 2008). Nevertheless, the essentiality of all the expected genes involved in quinate degradation could not be determined due to their lack at the time of the growth phenotyping (de Berardinis et al. 2008). 
Here, data for these mutants were incorporated to those previously published (Online Resource 2, Table S-9). All the genes coding for the enzymes involved in the transformation of quinate to succinyl-CoA and acetyl-CoA are essential, with the exception of $p c a D$ and pcaF (Fig. 1 and Online Resource 20). It was proposed that the dispensability of pcaD could be explained by the presence of the isofunctional gene catD (de Berardinis et al. 2008) and similarly, $p c a F$ could be complemented by $c a t F$. However, RNA-seq data indicated that although $p c a D$ and $p c a F$ were both highly up-regulated (117- and 443-fold respectively, Online Resource 2, Table S-4), catD and catF were not upregulated and only weakly transcribed (52 and 41 reads, respectively). These low expression levels may be not sufficient for substantial CatD and CatF activities and may suggest that other enzymes with overlapping substrate specificity were responsible for the rescue of the $p c a D$ and $p c a F$ deletions. For example, the degradation of dicarboxylic acids converges with the $\beta$-ketoadipate pathway at the level of $\beta$-ketoadipyl-CoA (Fig. 1). RNA-seq data indicated that the expression of $d c a F$, which is isofunctional with $p c a F$ and $c a t F$, was induced on quinate and may rescue $p c a F$ deletion. Alternatively, an increase in transcription of $c a t D$ and $c a t F$ in the corresponding mutants $\triangle$ ACIAD1708 $(\Delta p c a D)$ and $\triangle$ ACIAD1706 $(\triangle p c a F)$ could explain the dispensability of $p c a D F$. Further transcriptional analysis conducted in these mutants is required to confirm of this hypothesis. However, some mutants that show a growth defect could not be easily linked to the current knowledge of quinate metabolism and would thus require more investigation. For example, most of the genes of the nио operon (nиоAEFGHIJKMN), coding for NADH dehydrogenase $\mathrm{I}$, the proton-pumping NADH:ubiquinone oxidoreductase (respiratory complex I) that couples the electron transfer from NADH to ubiquinone with the translocation of protons across the membrane, were essential for growth on quinate (de Berardinis et al. 2008). This enzymatic complex was not required for growth on succinate, as succinate dehydrogenase (respiratory complex II) is a second entry point to the electron transport chain. But NADH dehydrogenase I was not either anticipated to be essential for growth on quinate since purified quinate dehydrogenase from Acinetobacter calcoaceticus transferred electrons from PQQ directly to ubiquinone (Adachi et al. 2003). More generally, PQQdependent membrane-bound dehydrogenases are supposed to feed electrons directly to ubiquinone in the respiratory chain and thus bypass the need for respiratory complex I (Yamada et al. 2003). Nevertheless, growth profiling results suggest that quinate dehydrogenase interacts with NADH I dehydrogenase for electron transfer. Likewise, it is surprising that genes that code for enzymes such as panD (ACIAD2911), glnE (ACIAD0596) and alkK (ACIAD1818), transport proteins (ACIAD1590 and 1601) or proteins of unknown function (ACIAD3137, 2741, 2176, and 2066) were also necessary for growth on quinate. The growth of all these mutants was not affected on other carbon sources such as acetate or glucose (de Berardinis et al. 2008), ruling out the possibility of a bias in their genetic construction and/or selection. This suggests that these genes are indeed related in some way to quinate catabolism.

\section{Concluding remarks}

The analysis of the ADPI transcriptome and metabolome confirmed that quinate triggered a specific transcriptional and metabolic response that allowed its dissimilation. But it essentially revealed that quinate elicited a global transcriptional response that affected $12 \%$ of the total number of the genes, most of them being of unknown function. We suggest that this global response, that was independent of the growth rate of the bacterium, was instead connected to its energy charge. These important changes in gene expression were reflected in the metabolome. Although metabolites of the central metabolism were not affected, the concentration of the majority of metabolites was indeed modified. Structural elucidation of some metabolites that were produced exclusively in quinate-grown cells is currently ongoing. It will help to find their associated genes and shed light on putative hidden metabolic pathways.

Acknowledgments This work was supported by Grants from Commissariat à l'Energie Atomique et aux Energies Alternatives (CEA), the CNRS and the University of Evry. LS was a recipient of $\mathrm{PhD}$ thesis fellowship from the Université d'Evry Val d'Essonne, Evry, France. We are grateful to M. Besnard-Gonnet for excellent technical assistance. We also thank M. Stam and D. Roche for helpful discussions and N. Fonknechten for useful comments on the manuscripts.

Open Access This article is distributed under the terms of the Creative Commons Attribution License which permits any use, distribution, and reproduction in any medium, provided the original author(s) and the source are credited.

\section{References}

Adachi, O., Yoshihara, N., Tanasupawat, S., Toyama, H., \& Matsushita, K. (2003). Purification and characterization of membrane-bound quinoprotein quinate dehydrogenase. Bioscience, Biotechnology, and Biochemistry, 67, 2115-2123.

Anders, S., \& Huber, W. (2010). Differential expression analysis for sequence count data. Genome Biology, 11, R106. doi:10.1186/ gb-2010-11-10-r106.

Bajad, S. U., Lu, W., Kimball, E. H., Yuan, J., Peterson, C., \& Rabinowitz, J. D. (2006). Separation and quantitation of water soluble cellular metabolites by hydrophilic interaction 
chromatography-tandem mass spectrometry. Journal of Chromatography A, 1125, 76-88. doi:10.1016/j.chroma.2006.05.019.

Barbe, V., Vallenet, D., Fonknechten, N., et al. (2004). Unique features revealed by the genome sequence of Acinetobacter sp. ADP1, a versatile and naturally transformation competent bacterium. Nucleic Acids Research, 32, 5766-5779. doi:10.1093/nar/gkh910.

Bastard, K., Thil Smith, A. A., Vergne-Vaxelaire, C., et al. (2013). Revealing the hidden functional diversity of an enzyme family. Nature Chemical Biology, doi:10.1038/NCHEMBIO.1387.

Brauer, M. J., Yuan, J., Bennett, B. D., et al. (2006). Conservation of the metabolomic response to starvation across two divergent microbes. Proc Natl Acad Sci U S A, 103, 19302-19307. doi:10. 1073/pnas.0609508103.

Brzostowicz, P. C., Reams, A. B., Clark, T. J., \& Neidle, E. L. (2003). Transcriptional cross-regulation of the catechol and protocatechuate branches of the beta-ketoadipate pathway contributes to carbon source-dependent expression of the Acinetobacter sp. strain ADP1 pobA gene. Applied and Environment Microbiology, 69, 1598-1606.

Bundy, B. M., Collier, L. S., Hoover, T. R., \& Neidle, E. L. (2002). Synergistic transcriptional activation by one regulatory protein in response to two metabolites. Proc Natl Acad Sci U S A, 99, 7693-7698. doi:10.1073/pnas.102605799.

Carlson, M., Pages, H., \& Aboyoun, P. et al. (2011). Tools for making and manipulating transcript centric annotations. $\mathrm{R}$ package version 1.4.3 In.

Chapman, A. G., Fall, L., \& Atkinson, D. E. (1971). Adenylate energy charge in Escherichia coli during growth and starvation. Journal of Bacteriology, 108, 1072-1086.

Coulier, L., Bas, R., Jespersen, S., Verheij, E., van der Werf, M. J., \& Hankemeier, T. (2006). Simultaneous quantitative analysis of metabolites using ion-pair liquid chromatography-electrospray ionization mass spectrometry. Analytical Chemistry, 78, 6573-6582. doi:10.1021/ac0607616.

Dal, S., Trautwein, G., \& Gerischer, U. (2005). Transcriptional organization of genes for protocatechuate and quinate degradation from Acinetobacter sp. strain ADP1. Applied and Environment Microbiology, 71, 1025-1034. doi:10.1128/AEM.71.2.1025-1034.2005.

D’Argenio, D. A., Segura, A., Coco, W. M., Bunz, P. V., \& Ornston, L. N. (1999). The physiological contribution of Acinetobacter PcaK, a transport system that acts upon protocatechuate, can be masked by the overlapping specificity of VanK. Journal of Bacteriology, 181, 3505-3515.

de Berardinis, V., Durot, M., Weissenbach, J., \& Salanoubat, M. (2009). Acinetobacter baylyi ADP1 as a model for metabolic system biology. Current Opinion in Microbiology, 12, 568-576. doi:10.1016/j.mib.2009.07.005.

de Berardinis, V., Vallenet, D., Castelli, V., et al. (2008). A complete collection of single-gene deletion mutants of Acinetobacter baylyi ADP1. Molecular Systems Biology, 4, 174. doi:10.1038/ msb.2008.10

DiMarco, A. A., Averhoff, B., \& Ornston, L. N. (1993). Identification of the transcriptional activator pobR and characterization of its role in the expression of pobA, the structural gene for $p$ hydroxybenzoate hydroxylase in Acinetobacter calcoaceticus. Journal of Bacteriology, 175, 4499-4506.

Durot, M., Le Fevre, F., de Berardinis, V., et al. (2008). Iterative reconstruction of a global metabolic model of Acinetobacter baylyi ADP1 using high-throughput growth phenotype and gene essentiality data. BMC Systems Biology, 2, 85. doi:10.1186/ 1752-0509-2-85.

Ewing, B., Hillier, L., Wendl, M. C., \& Green, P. (1998). Base-calling of automated sequencer traces using phred. I. Accuracy assessment. Genome Res, 8, 175-185.

Fiehn, O., Kopka, J., Dormann, P., Altmann, T., Trethewey, R. N., \& Willmitzer, L. (2000). Metabolite profiling for plant functional genomics. Nature Biotechnology, 18, 1157-1161. doi:10.1038/ 81137.

Fieller, E. C. (1954). Some problems in interval estimation. Journal of the Royal Statistical Society Series B (Methodology), 16, 175-185.

Fischer, R., Bleichrodt, F. S., \& Gerischer, U. C. (2008). Aromatic degradative pathways in Acinetobacter baylyi underlie carbon catabolite repression. Microbiology, 154, 3095-3103. doi:10. 1099/mic.0.2008/016907-0.

Frimmersdorf, E., Horatzek, S., Pelnikevich, A., Wiehlmann, L., \& Schomburg, D. (2010). How Pseudomonas aeruginosa adapts to various environments: A metabolomic approach. Environmental Microbiology, 12, 1734-1747. doi:10.1111/j.1462-2920.2010. 02253.x.

Gaude, E., Chignola, F., Spiliotopoulos, D., et al. (2013). muma, An R package for metabolomics univariate and multivariate statistical analysis. Current Metabolomics, 1, 180-189.

Gerischer, U., Jerg, B., \& Fischer, R. (2008). Spotlight on the Acinetobacter baylyi $\beta$-ketoadipate pathway: Multiple levels of regulation. In U. Gerischer (Ed.), Acinetobacter molecular biology (pp. 203-230). Norfolk: Caister Academic Press.

Harwood, C. S., \& Parales, R. E. (1996). The beta-ketoadipate pathway and the biology of self-identity. Annual Review of Microbiology, 50, 553-590. doi:10.1146/annurev.micro.50.1.553.

Hatfield, G. W., \& Benham, C. J. (2002). DNA topology-mediated control of global gene expression in Escherichia coli. Annual Review of Genetics, 36, 175-203. doi:10.1146/annurev.genet.36. 032902.111815.

Higgins, C. F., Dorman, C. J., Stirling, D. A., et al. (1988). A physiological role for DNA supercoiling in the osmotic regulation of gene expression in S. typhimurium and E. coli. Cell, 52, $569-584$.

Hsieh, L. S., Rouviere-Yaniv, J., \& Drlica, K. (1991). Bacterial DNA supercoiling and $[\mathrm{ATP}] /[\mathrm{ADP}]$ ratio: Changes associated with salt shock. Journal of Bacteriology, 173, 3914-3917.

Ibrahim, A., Gerner-Smidt, P., \& Liesack, W. (1997). Phylogenetic relationship of the twenty-one DNA groups of the genus Acinetobacter as revealed by $16 \mathrm{~S}$ ribosomal DNA sequence analysis. International Journal of Systematic Bacteriology, 47, 837-841.

Jones, R. M., Pagmantidis, V., \& Williams, P. A. (2000). sal genes determining the catabolism of salicylate esters are part of a supraoperonic cluster of catabolic genes in Acinetobacter sp. strain ADP1. Journal of Bacteriology, 182, 2018-2025.

Jones, R. M., \& Williams, P. A. (2001). areCBA is an operon in Acinetobacter sp. strain ADP1 and is controlled by AreR, a sigma(54)-dependent regulator. Journal of Bacteriology, 183, 405-409. doi:10.1128/JB.183.1.405-409.2001.

Joyard, J., \& Stumpf, P. K. (1980). Characterization of an acylcoenzyme a thioesterase associated with the envelope of spinach chloroplasts. Plant Physiology, 65, 1039-1043.

Kamleh, M. A., Hobani, Y., Dow, J. A., \& Watson, D. G. (2008). Metabolomic profiling of Drosophila using liquid chromatography Fourier transform mass spectrometry. FEBS Letters, 582, 2916-2922. doi:10.1016/j.febslet.2008.07.029.

Kim, J., Oliveros, J. C., Nikel, P. I., de Lorenzo, V., \& Silva-Rocha, R. (2013). Transcriptomic fingerprinting of Pseudomonas putida under alternative physiological regimes. Environ Microbiol Reports, doi:10.1111/1758-2229.12090.

King, R., Bonfiglio, R., Fernandez-Metzler, C., Miller-Stein, C., \& Olah, T. (2000). Mechanistic investigation of ionization suppression in electrospray ionization. Journal of the American Society for Mass Spectrometry, 11, 942-950. doi:10.1016/ S1044-0305(00)00163-X.

Klumpp, S., Zhang, Z., \& Hwa, T. (2009). Growth rate-dependent global effects on gene expression in bacteria. Cell, 139, 1366-1375. doi:10.1016/j.cell.2009.12.001. 
Li, H., Handsaker, B., Wysoker, A., et al. (2009). The sequence alignment/map format and SAMtools. Bioinformatics, 25, 2078-2079. doi:10.1093/bioinformatics/btp352.

Liu, M., Durfee, T., Cabrera, J. E., Zhao, K., Jin, D. J., \& Blattner, F. R. (2005). Global transcriptional programs reveal a carbon source foraging strategy by Escherichia coli. Journal of Biological Chemistry, 280, 15921-15927. doi:10.1074/jbc.M414050200.

Metzgar, D., Bacher, J. M., Pezo, V., et al. (2004). Acinetobacter sp. ADP1: An ideal model organism for genetic analysis and genome engineering. Nucleic Acids Research, 32, 5780-5790. doi:10.1093/nar/gkh881.

Nguyen, H. P., \& Schug, K. A. (2008). The advantages of ESI-MS detection in conjunction with HILIC mode separations: Fundamentals and applications. Journal of Separation Science, 31, 1465-1480. doi:10.1002/jssc.200700630.

Ning, Z., Cox, A. J., \& Mullikin, J. C. (2001). SSAHA: A fast search method for large DNA databases. Genome Research, 11, 1725-1729. doi:10.1101/gr.194201.

Oh, Y. K., Palsson, B. O., Park, S. M., Schilling, C. H., \& Mahadevan, R. (2007). Genome-scale reconstruction of metabolic network in Bacillus subtilis based on high-throughput phenotyping and gene essentiality data. Journal of Biological Chemistry, 282, 28791-28799. doi:10.1074/jbc.M703759200.

Romero-Arroyo, C. E., Schell, M. A., Gaines, G. L, 3rd, \& Neidle, E. L. (1995). catM encodes a LysR-type transcriptional activator regulating catechol degradation in Acinetobacter calcoaceticus. Journal of Bacteriology, 177, 5891-5898.

Siehler, S. Y., Dal, S., Fischer, R., Patz, P., \& Gerischer, U. (2007). Multiple-level regulation of genes for protocatechuate degradation in Acinetobacter baylyi includes cross-regulation. Applied and Environment Microbiology, 73, 232-242. doi:10.1128/ AEM.01608-06.

Smith, T. F., \& Waterman, M. S. (1981). Identification of common molecular subsequences. Journal of Molecular Biology, 147, 195-197.

Sumner, L. W., Amberg, A., Barrett, D., et al. (2007). Proposed minimum reporting standards for chemical analysis Chemical Analysis Working Group (CAWG) Metabolomics Standards Initiative (MSI). Metabolomics, 3, 211-221. doi:10.1007/ s11306-007-0082-2.

Tamhane, A. C., \& Logan, B. R. (2004). Finding the maximum safe dose level for heteroscedastic data. Journal of Biopharmaceutical Statistics, 14, 843-856.

Tautenhahn, R., Bottcher, C., \& Neumann, S. (2008). Highly sensitive feature detection for high resolution LC/MS. BMC Bioinformatics, 9, 504. doi:10.1186/1471-2105-9-504.

Tautenhahn, R., Patti, G. J., Rinehart, D., \& Siuzdak, G. (2012). XCMS Online: A web-based platform to process untargeted metabolomic data. Analytical Chemistry, 84, 5035-5039. doi:10. 1021/ac300698c.

Taylor, P. J. (2005). Matrix effects: The Achilles heel of quantitative high-performance liquid chromatography-electrospray-tandem mass spectrometry. Clinical Biochemistry, 38, 328-334. doi:10. 1016/j.clinbiochem.2004.11.007.

t'Kindt, R., Scheltema, R. A., Jankevics, A., et al. (2010). Metabolomics to unveil and understand phenotypic diversity between pathogen populations. PLoS Neglected Tropical Disease 4, e904 doi:10.1371/journal.pntd.0000904.

Vallenet, D., Belda, E., Calteau, A., et al. (2013). MicroScope-an integrated microbial resource for the curation and comparative analysis of genomic and metabolic data. Nucleic Acids Research, 41, D636-D647. doi:10.1093/nar/gks1194.

van der Werf, M. J., Overkamp, K. M., Muilwijk, B., et al. (2008). Comprehensive analysis of the metabolome of Pseudomonas putida S12 grown on different carbon sources. Molecular BioSystems, 4, 315-327. doi:10.1039/b717340g.

Van Dyk, T. K., Templeton, L. J., Cantera, K. A., Sharpe, P. L., \& Sariaslani, F. S. (2004). Characterization of the Escherichia coli AaeAB efflux pump: A metabolic relief valve? Journal of Bacteriology, 186, 7196-7204. doi:10.1128/JB.186.21.71967204.2004.

Walsh, K., \& Koshland, D. E, Jr. (1984). Determination of flux through the branch point of two metabolic cycles. The tricarboxylic acid cycle and the glyoxylate shunt. Journal of Biological Chemistry, 259, 9646-9654.

Wang, Z., Gerstein, M., \& Snyder, M. (2009). RNA-Seq: A revolutionary tool for transcriptomics. Nature Reviews Genetics, 10, 57-63. doi:10.1038/nrg2484.

Wilhelm, B. T., Marguerat, S., Goodhead, I., \& Bahler, J. (2010). Defining transcribed regions using RNA-seq. Nature Protocols, 5, 255-266. doi:10.1038/nprot.2009.229.

Williams, P. A., \& Kay, C. M. (2008). The catabolism of aromatic compounds. In U. Gerischer (Ed.), Acinetobacter molecular biology (pp. 99-117). Norfolk: Caister Academic Press.

Yamada, M., Elias, M. D., Matsushita, K., Migita, C. T., \& Adachi, O. (2003). Escherichia coli PQQ-containing quinoprotein glucose dehydrogenase: Its structure comparison with other quinoproteins. Biochimica et Biophysica Acta, 1647, 185-192.

Young, D. M., Parke, D., \& Ornston, L. N. (2005). Opportunities for genetic investigation afforded by Acinetobacter baylyi, a nutritionally versatile bacterial species that is highly competent for natural transformation. Annual Review of Microbiology, 59, 519-551. doi:10.1146/annurev.micro.59.051905.105823. 